Josep Quer*

\title{
On categorizing types of role shift in Sign languages
}

https://doi.org/10.1515/tl-2018-0020

Role shift is the widespread phenomenon in sign languages whereby a signer reports utterances, thoughts or actions of a character in another context by resorting to a possibly very rich array of nonmanual markers that imitatively depict the agent in that context. Such markers can include changes in eye gaze direction, facial expression, head and body position, and are mostly articulated simultaneously with manual signing. The stretches of signing marked with such nonmanual cues are interpreted by default with displaced reference to the derived context being reported. The literature that has undertaken a formal analysis of role shift has mostly focused on its use as a means to encode reported discourse, and it has addressed the question whether role shift is marking a direct quotation only or it encodes indirect reports as well. In this line of work, its use to report someone else's actions has been often put aside, despite the fact that in spontaneous discourse both uses occur intertwined with one another.

A complicating factor in tackling the phenomenon of role shift is the choice of labels used to refer to its different uses, which reflects an underlying categorization and certain analytical choices. One option has been to lump together all the phenomena marked with role shift under the term constructed action (e.g. Cormier et al. 2013), but it has been more common to distinguish the reportative use (constructed dialogue, as in Metzger 1995; attitude ascription, as in Quer 2013) and the use to refer actions by an agent (constructed action, as in Metzger 1995).

However, not all approaches agree as to what kind of production falls under the "action" use of role shift. For some researchers, it consists in the imitative reproduction of actions or gestures carried out by the agent being reported about. It often complements or illustrates the utterances or thoughts of the reported agent, normally in a richer fashion than co-speech gesture. An ASL example of this type of occurrence is illustrated in (1):

*Corresponding author: Josep Quer, ICREA - Departament de Traducció i Ciències del Llenguatge, Universitat Pompeu Fabra, Roc Boronat, 138, Barcelona 08018, Spain, E-mail: josep.quer@upf.edu 
(1) DECIDE DANCE [DANCE+++] THEN GIRL THINK. "PRO ${ }_{\mathbf{s t}}$ MUST GO HOME, PRO $_{1 \text { st }}$ MUST GO HOME."

'They decide to dance. They dance all around, and then the girl realizes, "I must go home, I must go home."

[ASL] (Emmorey 2002: 165)

In this example gestural action (indicated between square brackets) is naturally integrated in the narration, as part of it. From this perspective, role shift used to report action does not involve linguistic signs, but rather gestural production. ${ }^{1}$

Other researchers, though, draw the line differently and call constructed action or action role shift occurrences like example (3), minimally contrasting with the quotational example (2):

(2) HUSBAND REALLY I NOT MEAN

'The husband goes, "Really, I didn’t mean it."

(3) HUSBAND WORK

RS:husband

'The husband was like - "here I am, working."' [ASL] (Padden 1986: 49-50)

Lillo-Martin (2012) interprets these two cases as a kind of minimal pair that instantiates quotational vs. non-quotational role shift, respectively. The examples are marked with a stretch of role shift anchored to the referent of HUSBAND. According to Lillo-Martin (2012) (cf. also Engberg-Pedersen 1995; Lillo-Martin \& Quadros 2011), what distinguishes between the two uses is the appearance of a 1st person pronoun in (2), and its absence in (3). This correlation in ASL of presence vs. absence of 1st person pronoun with the quotative vs. non-quotative nature of the role fragment is capitalized upon and investigated in detail by Schlenker (this issue, 2017a, b). According to him, examples like (3) should be classified as action role shift, used "to display in a particularly vivid fashion some parts of the action through iconic means" (this issue: 162). Crucially, though, the report of the action from the agent's perspective is conveyed with actual signs coarticulated with role shift. The decisive factor that determines the two main uses of role shift, then, is the occurrence of first person indexicals or other markings in the action variety. This division between attitude and action role shift appears to be robust in ASL, and less so in French Sign Language (LSF).

1 For Davidson (2015), role shift used to report actions would involve the use of body classifiers, so from her perspective, strictly speaking these would be linguistic, non-gestural productions. 
Let us assume that this is the right partition of role shift functions or types, and that gestural, mimic-like reproduction of gestures falls outside the scope of action role shift. A possible difficulty is that the non-manual markers realizing role shift are shared by attitude and action role shift, on the one hand, and by gestural rendition of actions, on the other. One possible solution would be to say that role shift also includes co-sign gestures, in a parallel fashion to co-speech gesture. The question is whether they can be seen as somewhat parallel, given the much stronger integration of gesture into signed discourse.

However, the real empirical puzzle raised by the strict division of attitude vs. action role shift based on the presence or not of 1st person marking lies in the fact that attitude role shift is not only used to report declarative sentences that are about the intended agent, but also about other 2nd or 3rd person referents that the illocutionary agent talks about. It is unclear whether overt 2nd person pronouns and agreement, which are indexical too, have the same effect on the attitude vs. action divide in ASL. If so, the generalization would become even more robust, and it would predict that 3rd person pronouns directed towards (displaced) present vs. absent referents should create the same split in interpretation. This is, of course, an empirical matter that remains open.

Strictly linking the attitude use to the occurrence of indexical signs like the 1st person pronoun will wrongly exclude instances of attitude role shift that do not feature such elements. Take for instance a reported imperative as in (4) in Catalan Sign Language (LSC) ${ }^{2}$ :

\section{_RS:a}

imp

(4) PERSON CL:B $3 a \rightarrow 1$ STOP!

'A person approached me (and said): “Stop!”.'

Although there is no manual indexical marking in $(4)^{3}$ and no introductory element to flag the report, the only interpretation of role shift is that of quoting the utterance of the person that approached the signer. A similar case can be made for an example like (5), where role shift is flagging the report of a question:

2 The LSC data presented in this commentary have been elicited from two native signers (one female, one male, both middle-aged) from the Barcelona area.

3 One could argue that the eyegaze directed towards the inteded addressee (marking the command imperative) is indexical, thus triggering the quotative reading. This kind of indexicality, though, has not been taken into account in the works reviewed here. 
RS:a

wh

(5) PERSON CL:B $3 a \rightarrow 1$ METRO WHERE

'A person approached me (and asked): "Where's the metro?".'

Again, no indexical elements are to be found in the role shift fragment, but the only possible reading is that of a question report.

If similar facts to those just discussed hold in ASL, then the generalization about the impact of overt indexicals on role shift interpretation holds only in one direction: if an indexical is present under role shift, it will force an attitude reading; otherwise, it can give rise to both attitude or action readings.

Detailed cross-linguistic research on sign languages has shown that phenomena that look almost identical on the surface can diverge in terms of interpretation. A very relevant case at hand is the interpretation of indexicals under role shift, summarized by Schlenker (this issue): whereas in ASL and LSF indexicals under role shift must be invariably interpreted in the derived context marked by role shift, in LSC and German Sign Language (DGS) some indexicals under role shift can be still interpreted in the main context of utterance, giving rise to mixed perspectives. It is thus a good strategy to try figure out the details of a phenomenon in each particular language before drawing general conclusions for sign languages as a group. In the case of the attitude/action divide, Schlenker (2017a, b) has already reported differences between ASL and LSF.

Following the characterization offered for ASL and LSF, in principle one could expect that role shift in another sign language cuts role shift interpretations along the same line. Unexpectedly, though, LSC does not seem to allow for the action interpretation even in the absence of any indexical element in the scope of role shift, as illustrated in the following pairs of structures:

RS:a

(6) a. FATHER CL:B $3 a \rightarrow 1$ TIRED WORK

'Father approached me (and said): "I'm tired of working”/he was tired of working.'

RS:a

b. FATHER CL:B ${ }_{3 a \rightarrow 1}$ IX-1 TIRED WORK

'Father approached me (and said): "I'm tired of working”/he was tired of working.' 
(7) a. PERSON CL:B ${ }_{3 a \rightarrow 1} \overline{\text { FED-UP }}$

'A person approached me (and said): “I'm fed up!”/she was fed up.'

b. PERSON CL:B ${ }_{3 a \rightarrow 1}$ IX-1 FED-UP
'A person approached me (and said): “I'm fed up!”/she was fed up.'

[LSC]

In (6b) and (7b) the attitude reading is readily available, as expected because of the presence of IX-1. However, when the 1st person indexical is missing, as in (6a) and (7a), the reading obtained is exactly the same, but the unexpected fact is that these examples are not ambiguous and do not allow for an additional action reading (intended: 'Father approached me, looking tired of working' or 'A person approached me like she was fed up', respectively). This is a surprising result if one takes it for granted that the same phenomenon should essentially have the same properties across sign languages, but by now we know from growing comparative research that variation emerges when in depth work on individual sign languages is carried out, as much as across spoken languages.

Pending further empirical work on this issue, the question to be asked is whether LSC lacks the form of action role shift that has been attested and described for ASL (and LSF), whereas it is clear that role shift is also the hallmark of imitative, gesture-like reproduction of actions (body classifiers, in Davidson's (2015) approach) in this language, as part of reporting from an agent's perspective. A related thread to be explored is whether this further difference between the languages at stake is connected in some way to the difference in indexical interpretation mentioned above (obligatory vs. optional shifted interpretation of indexicals in role shift).

The findings in child acquisition of role shift, like the ones reported in Lillo-Martin \& Quadros (2011), should also help in some way to draw the partitions. According to their results, role shift is used at a very young age (1;07 and 1;11 for the first occurrences of their two subjects) for portraying the actions of others. For this purpose, children use non-manual marking including eye-gaze, facial expression and manner of movement correctly to indicate someone else's point of view. However, reported speech with role shift only occurs at a later stage. This acquisition path arguably tells us something substantial about the proper characterization of role shift types, but without more research the question remains open.

It might be a bit premature to circumscribe the term 'action role shift' to the ASL type, especially given the disparity of labels used so far to discuss this 
phenomenon, but Schlenker's work on it is certainly addressing a neglected core aspect of the whole phenomenon known as role shift that will further shed light on its grammatical and discourse properties.

Acknowledgements: The research in this paper was partly made possible thanks to the grants awarded to the author by the Spanish Ministry of Economy, Industry and Competitiveness and FEDER Funds (FFI2015-68 594-P), by the Government of the Generalitat de Catalunya (2017 SGR 1478) and by the European Commission (SIGN-HUB H2020 project 693 349).

\section{References}

Cormier, Kearsy, Sandra Smith \& Martine Zwets. 2013. Framing constructed action in British Sign Language narratives. Journal of Pragmatics 55. 119-139.

Davidson, Kathryn. 2015. Quotation, demonstration, and iconicity. Linguistics and Philosophy 38(6). 477-520.

Emmorey, Karen. 2002. Language, Cognition, and the Brain: Insights from Sign Language Research. Mahwah, NJ: Erlbaum.

Engberg-Pedersen, Elisabeth. 1995. Point of view expressed through shifters. In Karen Emmorey \& Judy S. Reilly (eds.), Language, Gesture, and Space, 133-154. Hillsdalle, NJ: Lawrence Erlbaum Associates.

Lillo-Martin, D. 2012. Utterance reports and constructed action in Sign and spoken languages. In Roland Pfau, Markus Steinbach \& Bencie Woll (eds.), Sign Languages. An International Handbook, 365-387. Berlin: Mouton.

Lillo-Martin, Diane \& Ronice M. De Quadros. 2011. Acquisition of the syntax-discourse interface: The expression of point-of-view. Lingua. International review of general linguistics. Revue internationale de linguistique generale 121. 623-636.

Metzger, Melanie. 1995. Constructed dialogue and constructed action in American Sign language. In Ceil Lucas (ed.), Sociolinguistics in Deaf Communities, 255-271. Washington, DC: Gallaudet University Press.

Padden, Carol. 1986. Verbs and Role-Shifting in American Sign language. In Carol Padden (ed.), Proceedings of the Fourth National Symposium on Sign Language Research and Teaching, 44-57. Silver Spring, MD: National Association of the Deaf.

Quer, Josep. 2013. Attitude ascriptions in Sign languages and role shift. In Leah C. Geer (ed.), Proceedings of the 13th Meeting of the Texas Linguistics Society, 12-28. Austin: Texas Linguistics Forum.

Schlenker, Philippe. 2017a. Super monsters I: Attitude and action role shift in Sign language. Semantics and Pragmatics 10(9). http://dx.doi.org/10.3765/sp.10.9.

Schlenker, Philippe. 2017b. Super monsters II: Role shift, iconicity and quotation in Sign language. Semantics and Pragmatics 10(12). 1-67. https://doi.org/10.3765/sp.10.12.

Schlenker, Philippe. This issue. Visible meaning: Sign language and the foundations of semantics. Theoretical Linguistics. 